\title{
Nonadditive effects of decomposing mixed foliar litter on the release of several metallic elements in a Pinus massoniana Lamb. forest
}

\author{
Wei He ${ }^{1} \cdot$ Lei Lei ${ }^{2,3} \cdot$ Zhiyuan Ma $^{1} \cdot$ Mingjun Teng ${ }^{1} \cdot$ Pengcheng Wang ${ }^{1} \cdot$ Zhaogui Yan $^{1} \cdot$ Zhilin Huang $^{2}$. \\ Lixiong Zeng ${ }^{1,2} \cdot$ Wenfa Xiao ${ }^{2,3}$
}

Received: 9 September 2019 / Accepted: 13 April 2020 / Published online: 18 May 2020

(C) INRAE and Springer-Verlag France SAS, part of Springer Nature 2020

\begin{abstract}
- Key message The mixture of decomposing litter from three predominant tree species in a Masson pine (Pinus massoniana Lamb.) forest showed advantages in elemental cycling, and the species component identities were found to be an important driver for the release of several metallic elements.

- Context Although mixed forests have long been considered essential to sustainable forestry management, little information is available regarding the effects of the mixed planting of predominant afforestation species on several metallic elements during litter decomposition in the Three Gorges Reservoir region, China.

- Aims The objectives of this study were to investigate the potential nonadditive effects on element loss from decomposing litter and to estimate the relationship between the mixing effect and the change in litter quality with environmental hydrothermal dynamics.

- Methods Treatments with one, two, or three species of pine, oak (Quercus variabilis Bl.) and cypress (Cupressus funebris Endl.) based on equal litter mass proportions were used in a field litter bag experiment, and the release of potassium, calcium, magnesium, manganese, iron, copper, zinc, and sodium was measured.

- Results Over the 360-day incubation period, most elements decayed faster in oak litter than in the other single-species treatments. A comparison of the litter mixtures revealed that most elements displayed their slowest decay in the pine+cypress combination, whereas the decay values obtained with the cypress+oak or pine+oak combinations were generally greater than those obtained with the pine+cypress+oak combination. Increases in the nonadditive effect on the release of metallic elements, with the exception of calcium, magnesium, and copper, were found in the different phases compared with the incubation time. Changes in elemental traits and environmental hydrothermal dynamics can regulate mixing effects on elemental decay in litter mixtures.

- Conclusion The mixing of the studied tree species can alter elemental cycling in plantations, and mixed planting with oak appears to strengthen the cycling process.
\end{abstract}

Handling Editor: Ana Rincón

Contribution of the co-authors L. Z., P. W., and W. X. designed the study. W. He., L. L., Z. M., M. T., Z. Y., and Z. H. performed the research. L. Z. proposed the structure of the paper and W. H. wrote the paper.

Lixiong Zeng zlxcaf@163.com

1 College of Horticulture and Forestry Sciences/Hubei Engineering Technology Research Center for Forestry Information, Huazhong Agricultural University, Wuhan 430070, China

2 Research Institute of Forest Ecology Environment and Protection/ State Forestry Administration Key Laboratory of Forest Ecology and Environment, Chinese Academy of Forestry, Beijing 100091, China

3 Co-Innovation Center for Sustainable Forestry in Southern China, Nanjing Forestry University, Nanjing 210037, China
Keywords Cupressus funebris · Multiple metallic elements · Nonadditive effect · Pinus massoniana $\cdot$ Quercus variabilis

\section{Introduction}

As a nutrient release process, leaf litter decomposition is an important pathway for the cycling of matter from plants to soil in forest ecosystems (Jonczak et al. 2014; Zhu et al. 2017). The rate of the release of metallic elements from litter is regulated by multiple factors, such as the chemical characteristics of the elements (Staaf and Berg 1982; Yue et al. 2019), the litter traits of the plant litter species and other factors related to the climate and in situ decomposers during the decomposition process (Swift et al. 1979). Potassium (K), calcium (Ca), and 
magnesium $(\mathrm{Mg})$ are usually released from leaf litter to soil during the decomposition process, whereas some trace elements, such as copper $(\mathrm{Cu})$, zinc $(\mathrm{Zn})$, manganese $(\mathrm{Mn})$, and sodium $(\mathrm{Na})$, are usually preferentially retained by microbes and show increased concentrations during the early phase of leaf litter decomposition (He et al. 2015; Jonczak et al. 2014). Thus, the elemental traits of litter likely significantly regulate the element dynamics in decomposing litter (Cornwell et al. 2008). The characteristics of the release of multiple metallic elements from different types of litter have been well studied (Jonczak et al. 2014; Lomander and Johansson 2001); however, the effects of species mixing on the release of these elements have seldom been investigated (Aponte et al. 2012).

The development of plantations related to the global commercial timber industry has been increasing (Wu et al. 2014). However, mixed forests have long been considered essential to sustainable forestry management (Brunel et al. 2017; Rodriguez-Loinaz et al. 2008). A higher biodiversity creates more varied habitats (Liu et al. 2016), enhances resilience to disturbances (FAO 2015), and can also improve matter cycling if the tree species composition is selected well (Zeng et al. 2018). However, alterations in the total physical surface of the in situ litter caused by different levels of component species have varying effects on the release of elements from mixed litter (Aponte et al. 2012). Theoretically, the physical abrasion or breakdown of litter mixtures involves several different processes (Swan et al. 2009), and scarce components might be transferred from decomposable litter to more resistant litter by fungal mycelia (Finzi and Canhamb 1998; Liu et al. 2016), thus contributing to the decomposition process. In contrast, the decomposition process might be inhibited by the identity of some specific species that possess abundant antimicrobial compounds such as tannins and polyphenols (Harrison 1971; Vivanco and Austin 2008). Accordingly, only considering the release characteristics of single-species components would not result in an accurate assessment of the dynamics of the decomposition of litter mixtures (Gartner and Cardon 2004). Multiple metallic elements, including some essential plant nutrients, such as $\mathrm{K}, \mathrm{Ca}$, and $\mathrm{Mg}$, can play crucial roles in plant physiology, whereas others, such as $\mathrm{Cu}$ and $\mathrm{Zn}$, can exert toxic effects on organisms when they exceed certain levels (Yue et al. 2016). A thorough understanding of the metallic element dynamics and their nonadditive effects associated with in situ litter decomposition is therefore indispensable for a better understanding of their role of plant communities and ecosystem function (Chapin III et al. 2002).

In the Three Gorges Reservoir area of China, tree species of Masson pine (Pinus massoniana Lamb.), weeping cypress (Cupressus funebris Endl.), and cork oak (Quercus variabilis B1.) have been widely planted (Ge et al. 2015). Decision makers usually implement mixed planting with two of these three species or all three species for the development of sustainable plantations (Zeng et al. 2018). Previous studies (Ge et al. 2015; Sun et al. 2012) and our recent work (Zeng et al. 2018) investigated the decay rate and nutrient release dynamics from litters obtained from one or more of these species. These results confirmed that the three dominant afforestation tree species in this area could facilitate the decomposition of litter mixtures in terms of mass loss and the release of carbon, nitrogen, and phosphorus, but the simultaneous release process of multiple metallic elements remains unexplored. The objectives of this study were (1) to assess the potential nonadditive effects of mixed leaf litter on the release of multiple metallic elements during decomposition and (2) to explore the relationship of the potential mixing effect and the changing litter quality (i.e., $\mathrm{C}, \mathrm{N}, \mathrm{P}$, and metallic elements) with environmental hydrothermal dynamics. The ability of oak to improve mixed litter nutrient cycling (in terms of mass loss and the release of $\mathrm{C}, \mathrm{N}$, and $\mathrm{P}$ ) during decomposition makes it a preferential tree species for mixed planting with cypress and pine (Zeng et al. 2018). The mechanisms underlying the synergistic interactions observed in mixtures with oak litter can be summarized as the transfer of abundant soluble materials and a heterogeneous physical habitat for decomposing organisms in a "mixed litter ecosystem" (He et al. 2019). Therefore, we hypothesized that oak leaf litter is of higher litter quality compared with that of pine and cypress (the corresponding lignin: $\mathrm{N}$ ratios are $6.8 \pm 0.4,11.7 \pm 0.0$, and $14.0 \pm 0.3$, respectively) and might also facilitate the cycling of metallic elements during mixed litter decomposition.

\section{Materials and methods}

\subsection{Experimental design}

We conducted a field litter bag experiment in a representative pine (Pinus massoniana Lamb.) forest in the Three Gorges Reservoir area of China (Zigui County, $110^{\circ} 00^{\prime}-111^{\circ} 18^{\prime} \mathrm{E}$, $30^{\circ} 38^{\prime}-31^{\circ} 11^{\prime} \mathrm{N}, 362 \mathrm{~m}$ a.s.l.) (He et al. 2020). The area has an annual average temperature of $18{ }^{\circ} \mathrm{C}$, with maximal and minimum temperatures of $44{ }^{\circ} \mathrm{C}$ and $-2.5^{\circ} \mathrm{C}$, respectively. The annual sunshine time is $1620 \mathrm{~h}$, the relative air humidity is $77 \%$, and the number of frost-free days ranges from 300 to 340. Approximately $75 \%$ (1000 to $1025 \mathrm{~mm}$ ) of the annual precipitation occurs from April to September. The local trees are dominated by Pinus massoniana Lamb., Cupressus funebris Endl., and Quercus variabilis B1., although Cunninghamia lanceolata Hook. and Pinus tabuliformis Carr. are also common. The understory shrubs are dominated by Camellia oleifera Abel., Loropetalum chinense Oliv., Viburnum erosum Thunb., Echinochloa crus-galli (L.) P. Beauv., Dicranopteris linearis Underw., and other species. The soils are dominated by Haplic luvisol. A complete description of the study site was published by Zeng et al. 
(2018). The experiments were performed in three replicate plots $(5 \times 5 \mathrm{~m})$ with similar canopy structures that were located at least $200 \mathrm{~m}$ from one another within the pine forest.

The soil and litter of the species used for the incubation experiment were collected from natural pine, cypress (Cupressus funebris Endl.) and oak (Quercus variabilis B1.) forests in November 2014. The collected leaf litter was airdried for 2 weeks at room temperature. For preparation of the litter bags, $10 \mathrm{~g}$ of air-dried samples from each species with three replicates each were collected and oven-dried at $65{ }^{\circ} \mathrm{C}$ for $48 \mathrm{~h}$ to calculate the moisture correction factor. For each litter bag used for each treatment, $15 \mathrm{~g}$ of air-dried litter sample was placed in $15 \times 15 \mathrm{~cm}$ nylon bags with a $1.0-\mathrm{mm}$ mesh width. Seven combination treatments were used to assess the nonadditive effects: individual litter bags of pine, cypress, and oak, pairwise combinations of the three species (i.e., pine+ cypress, pine+oak, and cypress+oak, $7.5 \mathrm{~g}$ of each component species), and a combination of all three species (pine+cypress+oak, $5 \mathrm{~g}$ of each component species). During the preparation of the litter bags in the laboratory, subsamples from each oven-dried litter were analyzed to determine the initial nutrient concentrations (Fig. 1 and Table 1).
To avoid the "home-field" advantage (Ayres et al. 2009; Chomel et al. 2015) and ensure similar initial microbial compositions, topsoil was collected from the 0 to $10 \mathrm{~cm}$ layer of the three natural forests from which the litters were collected. After removal of the coarse materials, these soils were mixed, sieved through a $2-\mathrm{mm}$ sieve, and then used to fill plastic pots measuring $15 \mathrm{~cm}$ (diameter) $\times 20 \mathrm{~cm}$ (height). The basic soil properties of the mixture were as follows: organic C, $22.42 \pm$ $0.20 \mathrm{~g} \mathrm{~kg}^{-1}$; total $\mathrm{N}, 0.75 \pm 0.01 \mathrm{~g} \mathrm{~kg}^{-1}$; total $\mathrm{P}, 0.25 \pm$ $0.01 \mathrm{~g} \mathrm{~kg}^{-1}$; available $\mathrm{P}, 5.00 \pm 0.20 \mathrm{mg} \mathrm{kg}$; total K, 7.38 $\pm 0.12 \mathrm{~g} \mathrm{~kg}^{-1}$; and pH, $4.65 \pm 0.02(n=5)$.

A total of 378 plastic pots with litter bags ( 3 plots $\times 7$ litter treatments $\times 3$ replicates $\times 6$ sampling events) were randomly placed on the floor of the established experimental plots on December 6, 2014, and each of the placed pots was held by sticks. Nylon gauze $(0.05-\mathrm{mm}$ mesh width) was placed over the experimental plots to exclude the litterfall from the standing forest. To quantify the temporal mixture effects and their relationships with the changing litter substrates and local environmental factors, we sampled the litter bags six times during the a 1 -year incubation period, namely after $60,120,180$, 240,300 , and 360 days of incubation. Temperature and
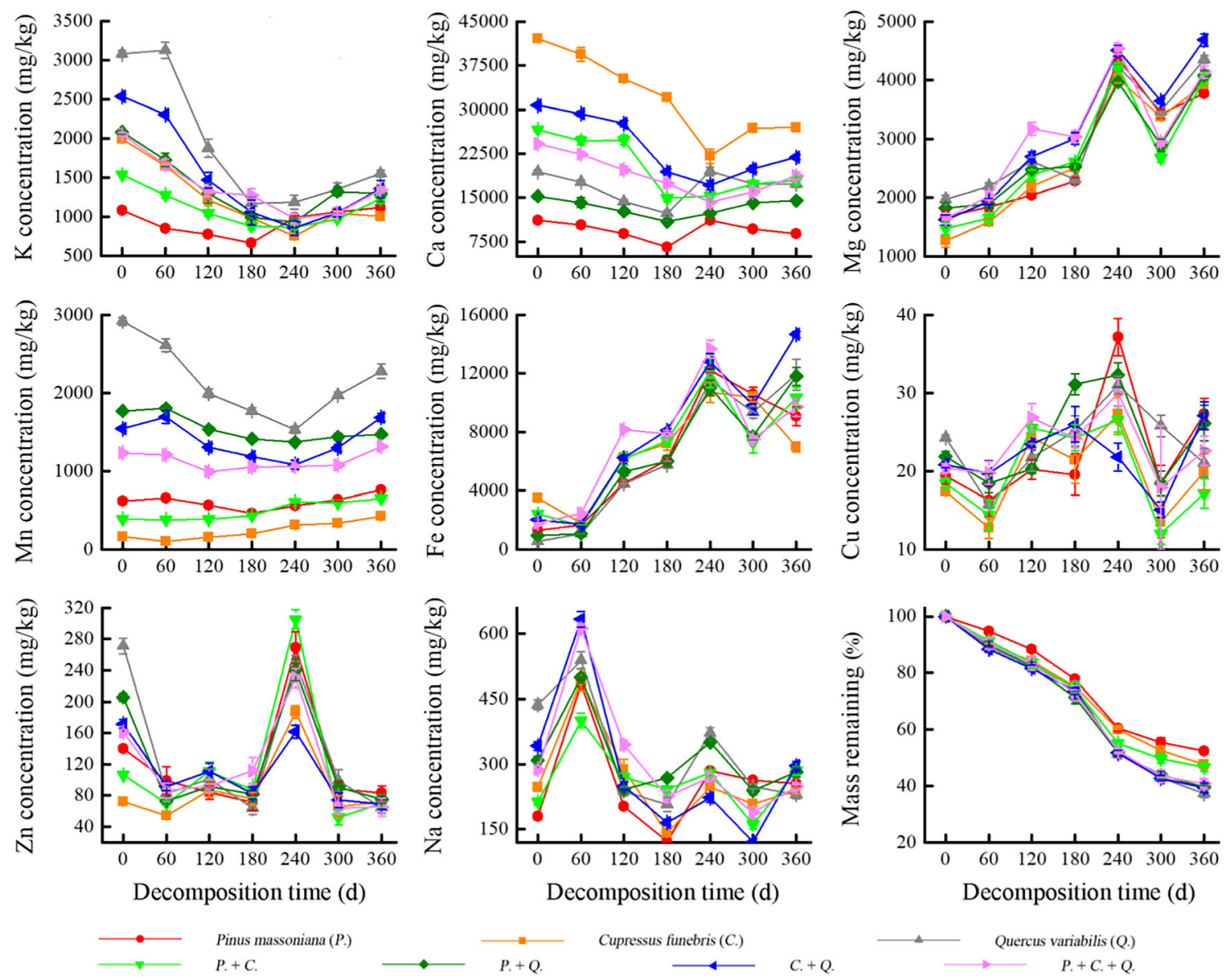

Fig. 1 Dynamics of the metallic element concentrations and remaining mass in the treatments $(P .+C ., P$. massoniana $+C$. funebris; $P .+Q ., P$. massoniana $+Q$. variabilis; and so on) over the decomposition time (means \pm SEs, $n=3$ ) 
Table 1 Initial litter chemistry (means \pm SEs, $n=3$ )

\begin{tabular}{|c|c|c|c|c|c|c|}
\hline Treatments & $\begin{array}{l}\text { Carbon } \\
\left(\mathrm{g} \cdot \mathrm{kg}^{-1}\right)\end{array}$ & $\begin{array}{l}\text { Nitrogen } \\
\left(\mathrm{g} \cdot \mathrm{kg}^{-1}\right)\end{array}$ & $\begin{array}{l}\text { Phosphorus } \\
\left(\mathrm{g} \cdot \mathrm{kg}^{-1}\right)\end{array}$ & Lignin (\%) & $\mathrm{C} / \mathrm{N}$ & Lignin:N \\
\hline $\begin{array}{l}\text { Pinus } \\
\quad \text { massoniana } \\
\quad(P .)\end{array}$ & $438.1 \pm 3.5 \mathrm{a}$ & $16.3 \pm 0.3 \mathrm{c}$ & $0.42 \pm 0.01 \mathrm{c}$ & $22.9 \pm 0.1 b$ & $26.8 \pm 0.3 \mathrm{a}$ & $14.0 \pm 0.3 \mathrm{a}$ \\
\hline $\begin{array}{l}\text { Cupressus } \\
\quad \text { funebris }(C .)\end{array}$ & $380.9 \pm 1.5 c$ & $22.2 \pm 0.1 b$ & $0.73 \pm 0.02 b$ & $26.1 \pm 0.1 \mathrm{a}$ & $17.1 \pm 0.1 \mathrm{~b}$ & $11.7 \pm 0.0 \mathrm{~b}$ \\
\hline $\begin{array}{l}\text { Quercus } \\
\text { variabilis (Q.) }\end{array}$ & $424.6 \pm 0.2 b$ & $27.5 \pm 0.0 \mathrm{a}$ & $0.81 \pm 0.01 \mathrm{a}$ & $18.8 \pm 1.2 \mathrm{c}$ & $15.4 \pm 0.0 \mathrm{c}$ & $6.8 \pm 0.4 \mathrm{c}$ \\
\hline$P .+C$ & $409.5 \pm 2.2$ & $19.3 \pm 0.1$ & $0.58 \pm 0.02$ & $24.5 \pm 0.1$ & $21.2 \pm 0.0$ & $12.7 \pm 0.1$ \\
\hline$P .+Q$. & $431.3 \pm 1.8$ & $21.9 \pm 0.2$ & $0.61 \pm 0.01$ & $20.8 \pm 0.7$ & $19.7 \pm 0.1$ & $9.5 \pm 0.2$ \\
\hline C. $+Q$ & $402.7 \pm 0.9$ & $24.9 \pm 0.0$ & $0.77 \pm 0.02$ & $22.4 \pm 0.7$ & $16.2 \pm 0.0$ & $9.0 \pm 0.3$ \\
\hline$P .+C .+Q$. & $414.5 \pm 1.5$ & $22.0 \pm 0.1$ & $0.65 \pm 0.01$ & $22.6 \pm 0.5$ & $18.9 \pm 0.0$ & $10.3 \pm 0.2$ \\
\hline
\end{tabular}

Treatments: $\mathrm{P}+\mathrm{C}$, P. massoniana + C. funebris; $\mathrm{P}+\mathrm{Q}$, P. massoniana + Q. variabilis; and so on

Different lowercase letters indicate a significant difference between individual species for a given variable at $P<0.05$ precipitation data were collected from the local weather station (Fig. 2).

\subsection{Analyses and calculations}

After the foreign roots were removed from the litter bags, the retrieved litter was oven-dried at $65^{\circ} \mathrm{C}$ to a constant mass (at least $48 \mathrm{~h}$ ) and then weighed. Thereafter, the oven-dried samples were ground in a mill and then sieved through a $0.3-\mathrm{mm}$ mesh screen

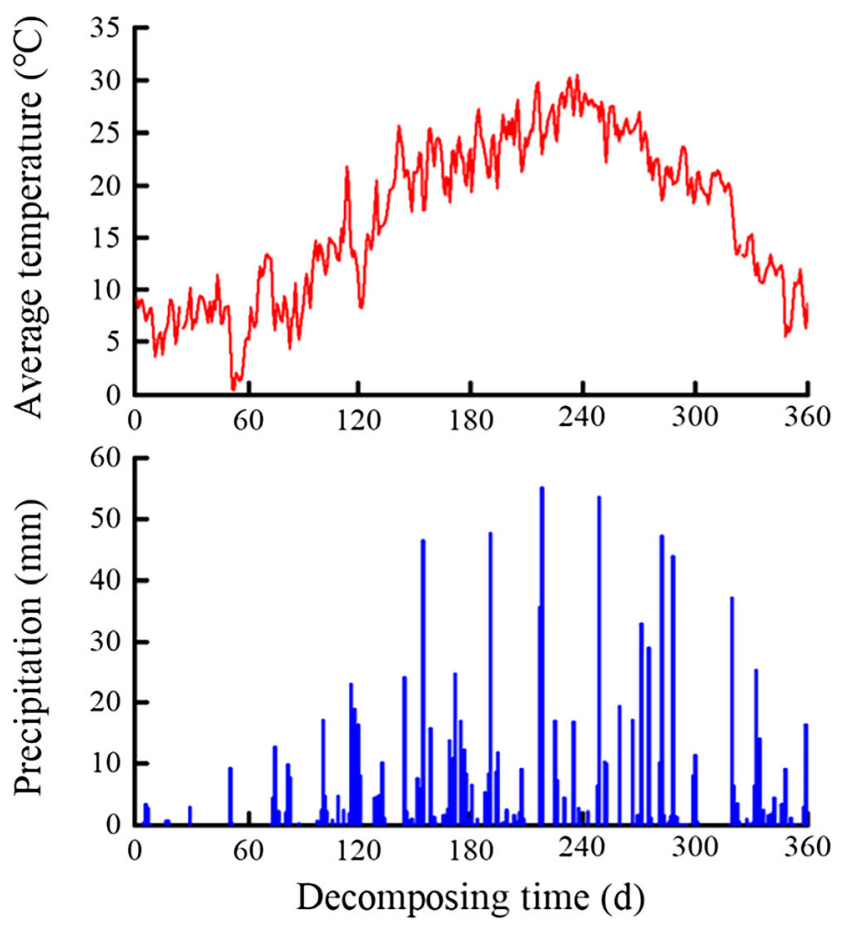

Fig. 2 Dynamics of the daily average temperature (a) and precipitation (b) from December 6, 2014, to November 30, 2015 (totaling 360 days of exposure). The $\mathrm{X}$-axis shows the decomposition time in days from the time of litter bag placement for measurements of the elemental concentrations. The powdered leaf litter from both the initial and decomposed samples was solved in a concentrated acidic mixture of $\mathrm{HNO}_{3}-\mathrm{HClO}_{4}(5: 1$, $\mathrm{v} / \mathrm{v}$ ) and heated at $160{ }^{\circ} \mathrm{C}$ for $5 \mathrm{~h}$. The concentrations of $\mathrm{K}, \mathrm{Ca}$, $\mathrm{Mg}, \mathrm{Mn}, \mathrm{Fe}, \mathrm{Cu}, \mathrm{Zn}$, and $\mathrm{Na}$ were determined using an inductively coupled plasma mass spectrometer (ICP-MS, IRIS Advantage 1000, Thermo Elemental, Waltham, MA, USA) (Yue et al. 2016). The methods used to determine the initial concentrations of $\mathrm{C}, \mathrm{N}, \mathrm{P}$, and lignin were described by Zeng et al. (2018) and He et al. (2019).

To characterize the abiotic factors in each sampling phase (defined as the time from the previous to the current sampling dates), the average temperature (AT) and cumulative precipitation were calculated from the daily mean temperatures and precipitation (Table 2). The release of multiple metallic elements $(R)$ during each phase of incubation was calculated as follows:

$R_{t}(\%)=\left(C_{(t-1)}-C_{t}\right) / C_{t 0} \times 100$

where $C_{(t-1)}$ and $C_{t}$ represent the content (mg) of metallic elements on the previous and current sampling dates, respectively, and $\mathrm{C}_{t 0}$ is the initial content of the metallic elements. The cumulative element release during the total decomposition time was the

Table 2 Average temperature $\left(\mathrm{AT},{ }^{\circ} \mathrm{C}\right)$ and accumulated precipitation $(\mathrm{mm})$ at each phase of the decomposition process

\begin{tabular}{lll}
\hline Phase & AT & Cumulative precipitation \\
\hline $0-60$ days & 6.8 & 20.6 \\
$61-120$ days & 10.9 & 128.9 \\
$121-180$ days & 19.6 & 252.2 \\
$181-240$ days & 25.2 & 253.2 \\
$241-300$ days & 24.6 & 296.0 \\
$301-360$ days & 15.2 & 144.9 \\
\hline
\end{tabular}


sum of the corresponding values found for the different phases.

To assess the nonadditive effects, the expected metallic release $(T R)$ from the litter mixtures (calculated from the observed release characteristics observed for the single-species treatment of the corresponding component) was calculated using the following formula (Gartner and Cardon 2004):

$T R_{t}(\%)=\left(R_{A t}+\ldots+R_{n t}\right) / N$

where $N$ is the number of species in the mixture and $R_{n t}$ is the measured elemental release in the bag containing only the nth species.

\subsection{Statistical analyses}

An independent $t$ test with an alpha level of 0.05 was used to determine the difference between the observed and expected values for the release of multiple metallic elements. The mixing effects were classified as significant nonadditive effects if significant differences were found between the observed and expected values (Mao and Zeng 2012; Hättenschwiler et al. 2005). Furthermore, in the current study, an observed value that was significantly greater than the expected value indicated a significantly synergistic effect, whereas an observed value that was significantly less than the expected value represented a significantly antagonistic effect.

In addition, prior to statistical analysis, the data were tested for normality and homogeneity $\left(\arcsin \left(\mathrm{x}^{\wedge} 0.5\right)\right.$ transformation was used in the case of no homogeneity). After the general ANOVA hypothesis was verified, detailed post hoc mean comparisons of significant differences in the litter variables among the treatments were performed using Tukey's HSD. The sampling time and a nested factor of the litter mixture treatments were inputted as fixed factors into an univariate ANOVA, and a two-way ANOVA of the nested model was used to examine the effects of the two factors on the release of multiple metallic elements. A univariate regression analysis was conducted using the release of multiple metallic elements at the different phases as the response variable and the temporal chemical traits or abiotic factors as the predictor variables. The same approach was used to assess the effect of the litter mixture on the release of multiple metallic elements (i.e., observed value minus expected value) at each phase as the response variable. The Statistical Product and Service Solutions program (SPSS 21.0 for Windows; SPSS Inc., Chicago, IL, USA) was used to perform all the analyses.

\section{Results}

\subsection{Metallic element release rates}

The metallic element release rates both increased and decreased during the decomposition time, as shown in Fig. 3.
Over the 360-day decomposition period, the initial litter element mass showed $697.9 \%$ accumulation to $91.2 \%$ loss depending on the litter treatments and the type of metallic element. The release rate of all the investigated metallic elements from the mixed litters was not lower than the lowest values or higher than the highest values obtained for the single-species treatments with the corresponding species (except for the release of $\mathrm{Ca}$ and $\mathrm{Na}$ after 240 days).

After 60 days of decomposition (Fig. 3), the release of K and $\mathrm{Na}$ from oak litter was significantly faster than the rates from the other two single-species litters $(F=8.8$ to 744.9, $P<0.05)$. A similar trend was found for the release of $\mathrm{Ca}$, although the release rate from cypress litter after 240 days was significantly higher $(F=45.7$ to $74.6, P<0.001)$. The comparisons of the three single-species litter treatments revealed that the fastest release of $\mathrm{Mg}, \mathrm{Mn}, \mathrm{Cu}$, and $\mathrm{Zn}$ was obtained with oak litter $(F=5.4$ to $1158.0, P<0.05)$, although negative values for the release of these elements (i.e., accumulation) were sometimes obtained with the other two litter treatments. Substantial accumulation of Fe was observed, and a higher accumulation of this element was found in oak litter ( $F=109.5$ to $4522.6, P<0.001)$.

The comparisons of the litter mixtures showed that the release rates of $\mathrm{K}, \mathrm{Mg}, \mathrm{Mn}, \mathrm{Zn}$, and $\mathrm{Na}$ from pine+cypress litter were almost always lower than those found with the other three mixed treatments ( 24 of 30 cases, Fig. 3). Some of the highest $\mathrm{Mg}$ and $\mathrm{Cu}$ release rates were observed with the pine+cypress+oak combination, and the highest release rates of $\mathrm{K}, \mathrm{Ca}, \mathrm{Mg}, \mathrm{Mn}, \mathrm{Zn}$, and $\mathrm{Na}$ obtained with the pine+oak or cypress+oak combinations were greater than those found with the pine+cypress+oak combination. The accumulation of $\mathrm{Fe}$ was lowest in the pine+cypress combination and highest in the pine+oak combination. Moreover, the statistical analyses showed that changes in the litter quality and environmental factors (average temperature and/or cumulative precipitation) can have significant influences on the release of multiple elements at different phases, regardless of whether the litter is from a single species or multiple species (Table 3 ).

\subsection{Synergistic or antagonistic interactions in litter mixtures}

The nonadditive effects obtained for all the investigated metallic elements in the tested mixtures (four mixtures and six sampling dates) showed variations among the combinations and decomposition times (Fig. 4). Among the tested metallic elements, immediate significant synergistic or antagonistic effects (exposure for only 60 days) was found on the releases of $\mathrm{K}, \mathrm{Mn}, \mathrm{Fe}, \mathrm{Cu}, \mathrm{Zn}$, and Na. Significant antagonistic interactions on the release of $\mathrm{Ca}$ and $\mathrm{Mg}$ were found after 120 days of decomposition. However, no nonadditive effect was found on the release of $\mathrm{K}, \mathrm{Mg}$, and $\mathrm{Zn}$ among the tested combinations at the end of the study period. Significant synergistic interactions 
Fig. 3 Metallic element release rates from monospecific and mixed leaf litters of

P. massoniana, C. funebris, and Q. variabilis during 360 days of decomposition (the values are presented as the means \pm SEs, $n=$ 3). The two-way ANOVA (the litter mixture treatment was treated as a nested factor) results suggest that the litter mixture treatment $\left(F_{(6,84)}=14.873\right.$ to $1098.045, P<0.001)$ and decomposition time $\left(F_{(35,84)}=16.569\right.$ to 572.851, $P<0.001)$ have significant effects on the cumulative metallic element release rates. Different lowercase letters indicate significant differences $(P<0.05)$ among different litter types for the same decomposition time
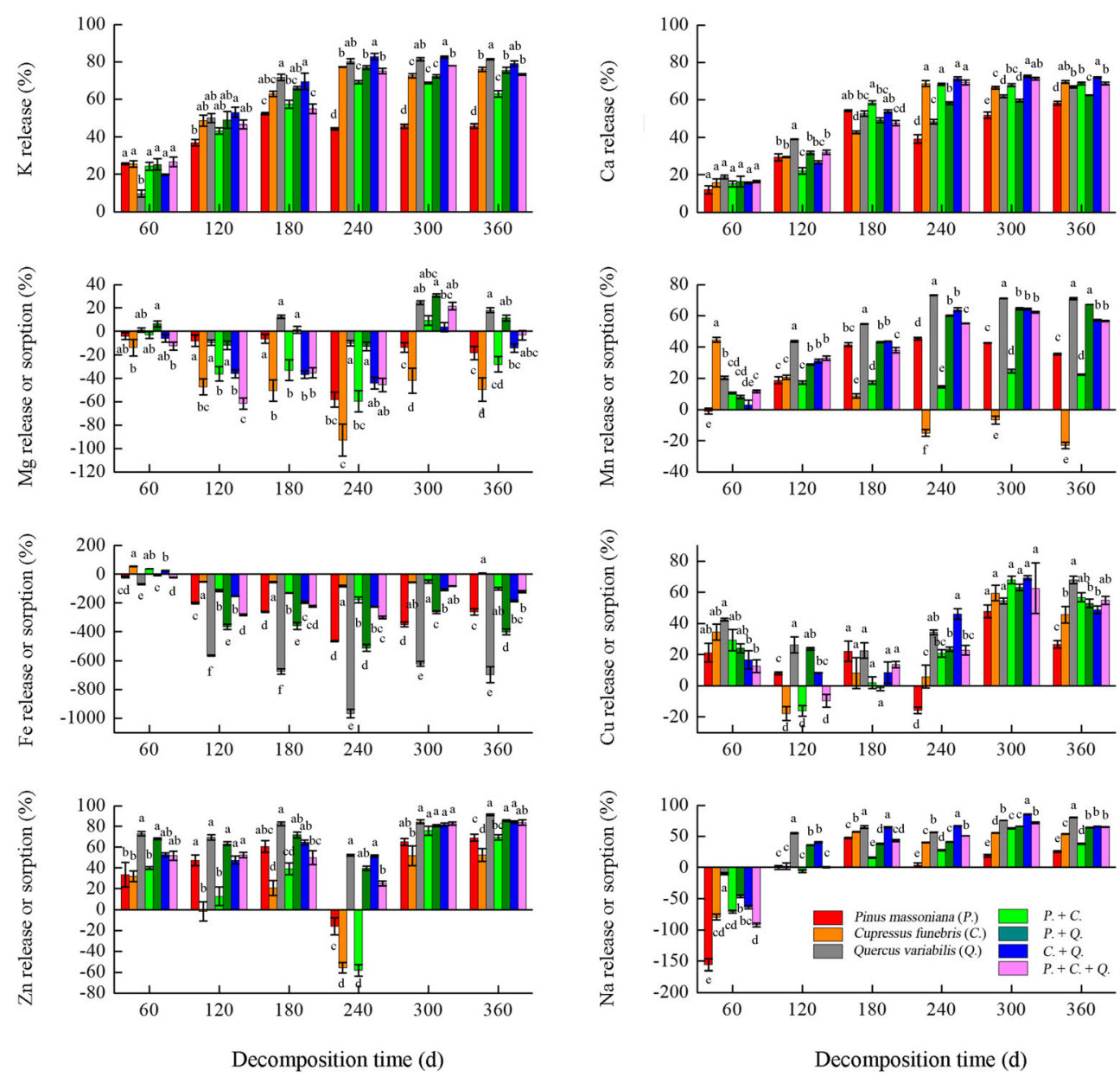

on the release of $\mathrm{K}, \mathrm{Ca}, \mathrm{Mg}, \mathrm{Mn}, \mathrm{Fe}, \mathrm{Cu}, \mathrm{Zn}$, and $\mathrm{Na}$ accounted for $29.2 \%, 41.7 \%, 16.7 \%, 4.2 \%, 25.0 \%, 33.3 \%$, $8.3 \%$, and $37.5 \%$ of all cases, respectively (corresponding to $7,10,4,1,6,8,2$, and 9 significant synergistic interactions among 24 cases). Significant antagonistic interactions on the release of $\mathrm{K}, \mathrm{Ca}, \mathrm{Mg}, \mathrm{Mn}, \mathrm{Fe}, \mathrm{Cu}, \mathrm{Zn}$, and $\mathrm{Na}$ accounted for $4.2 \%, 12.5 \%, 12.5 \%, 79.2 \%, 50.0 \%, 20.8 \%, 8.3 \%$, and $37.5 \%$ of all cases, respectively (corresponding to 1, 3, 3, 19, 12, 5, 2, and 9 significant antagonistic interactions among 24 cases).

For all the sampled mixtures (four mixtures and six incubation phases), the incidence of significant nonadditive effects on the release of the investigated metallic elements, with the exception of $\mathrm{Ca}, \mathrm{Mg}$, and $\mathrm{Cu}$, increased over the different phases compared with decomposition time (Fig. 5). Specifically, $58.4 \%, 62.5 \%, 79.2 \%, 45.8 \%, 50.0 \%$, and $87.5 \%$ of the cases showed significant interactions on the release of $\mathrm{K}, \mathrm{Mn}, \mathrm{Fe}, \mathrm{Zn}$, and $\mathrm{Na}$, respectively (corresponding to $14,15,19,11,12$, and 21 significant synergistic and antagonistic interactions among the 24 cases). Regression analyses revealed that dynamic environmental factors can exert a significant effect on the release of $\mathrm{Mg}, \mathrm{Mn}, \mathrm{Fe}, \mathrm{Cu}, \mathrm{Zn}$, and $\mathrm{Na}$. Notably, the mixing effects on the release of $\mathrm{Mg}, \mathrm{Mn}$, and $\mathrm{Fe}$ were closely correlated with changes in the quality of the investigated elements (Table 4).

\section{Discussion}

\subsection{Effect of the species composition on release of metallic elements from litter combinations}

The results of this study indicated that the tree species and composition altered the metallic element release dynamics and induced nonadditive effects during the course of decomposition. In addition, regardless of the differences in the decay characteristic of multiple metallic elements, the pattern found for the release of these metallic elements from litter mixtures showed significant differences among the diverse combinations. Previous studies have suggested that each of the predominant afforestation tree species in the Three Gorges Reservoir area plays a unique role in the nutrient cycling process associated with decomposition in planted-forest ecosystems (Zeng et al. 2018). 


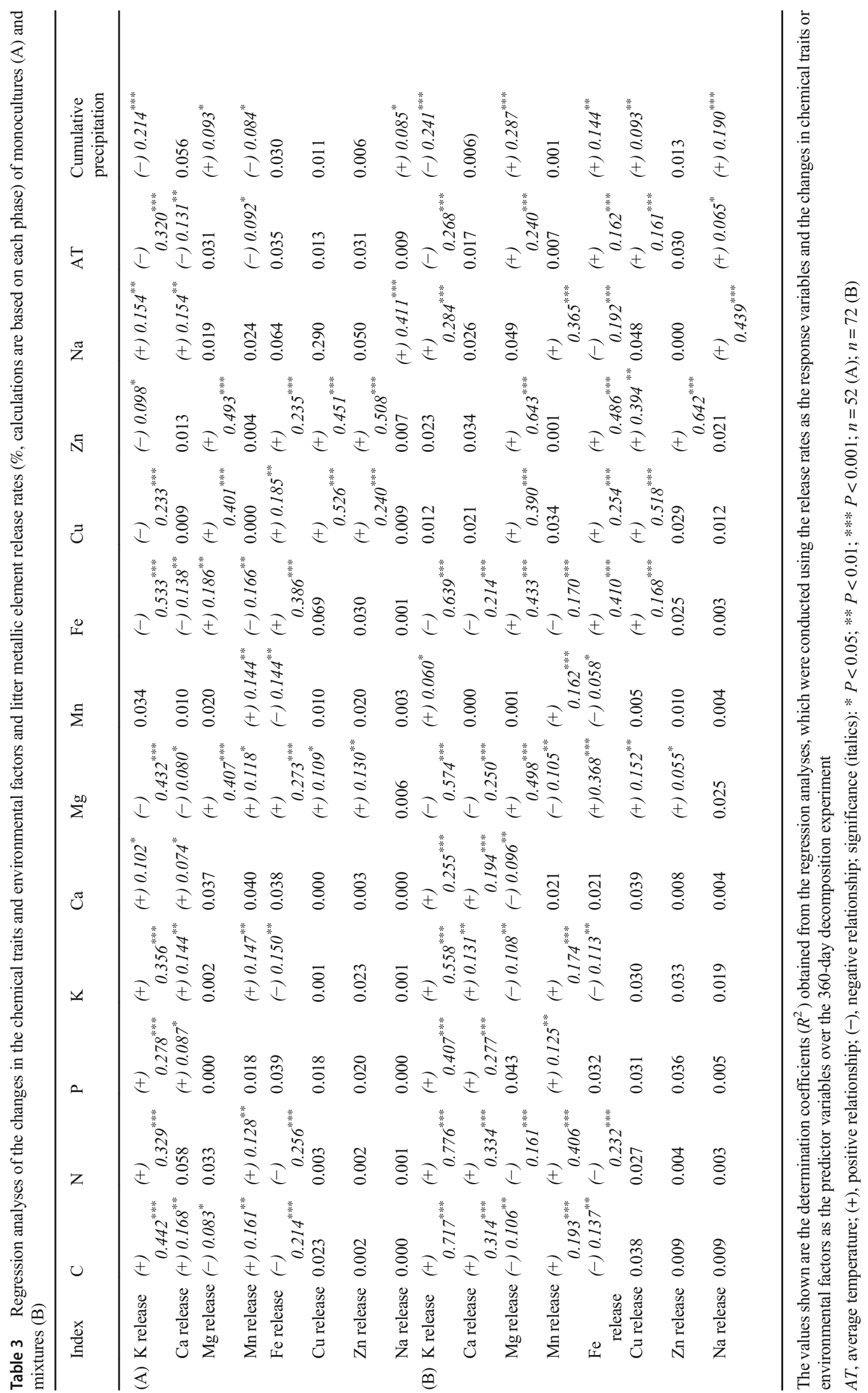


We hypothesized that the tested oak species, which showed superior decay characteristics in terms of litter quality (relatively less recalcitrant characteristics), could accelerate the decomposition process of the other tree species. Indeed, the decomposition characteristics of most metallic elements displayed faster release rates from oak litter than from the other two single-species litters in the current study (Fig. 3). However, with the exception of the release of $\mathrm{Ca}$ and $\mathrm{Na}$ after 240 days, the release rates of all the investigated metallic elements from the mixtures were not lower than the lowest values or higher than the highest values obtained with the corresponding single-species treatments. The results were consistent with the present consensus, which agrees that an admixture of higher-quality litter can accelerate the decomposition of more resistant litters and vice versa (Briones and Ineson 1996; McTiernan et al. 1997; Cuchietti et al. 2014; Wu et al. 2014). Among the tested mixtures, lower and higher release rates for most metallic elements were always obtained with the pine+cypress combination and the pine+oak or cypress+oak combination, respectively. Among the three tree species, oak had relatively higher $\mathrm{N}$ and lower lignin/ $\mathrm{N}$ (Table 1). The increase in abundance of pine and oak litter seemed to significantly decrease and increase the release rates from mixed litter, respectively. These findings coincide with the theory that the identity of specific species is an important driver of the overall diversity effect on decomposition (Gessner et al. 2010; Pérez et al. 2007). Thus, for the acceleration of element circulations, oak should be used as the preferential tree species for mixed planting in the Three Gorges
Reservoir area of China based on its contribution to elemental cycling.

Interestingly, we observed that most of the metallic elements exhibited greater release or accumulation rates in the pine+oak or cypress+oak combination compared with the pine+cypress+oak combination (Fig. 3). Previous studies have indicated that the species composition influences the nonadditive effects in litter mixtures (Lecerf et al. 2007; $\mathrm{Wu}$ et al. 2013), whereas other studies have suggested that increased species diversity can increase the incidence of nonadditive effects (Hättenschwiler et al. 2005; Keith et al. 2008; Duan et al. 2013). The results of the current study further suggest that the species composition rather than the species richness (although the species richness was only three in our study) has a significant influence on nonadditive decomposition of multiple metallic elements in mixed plantations of the three predominant species in the Three Gorges Reservoir area of China. A recent study by Steinwandter et al. (2019) also showed that higher-quality litter had more positive effects on a low-quality litter (the litter quality of components in a combination is a key factor), although accelerated decomposition rates were found in a three-species treatment. Multiple element release by both single-species and mixed-species treatments exhibits a significant relationship with changing litter quality (Table 3), and these results also support the hypothesis that specific species (Swift et al. 1979) and species composition (Gartner and Cardon 2004) are more influential than other factors on the decomposition process.
Fig. 4 Effects of the treatments on the metallic element release rates during decomposition. The values are presented as the means \pm SEs $(n=3)$. A positive value indicates that the observed value is greater than the expected value and vice versa. Statistical significance levels: *, $P<0.05$; $* *, P<0.01$; and ***, $P<0.001$. The inset values indicate the proportion of the corresponding significant interactions (synergistic and antagonistic interactions above and below the zero line, respectively) in a total of 24 cases. Treatments: $P .+C$., $P$. massoniana $+C$. funebris; $P .+Q ., P$. massoniana $+Q$. variabilis; and so on
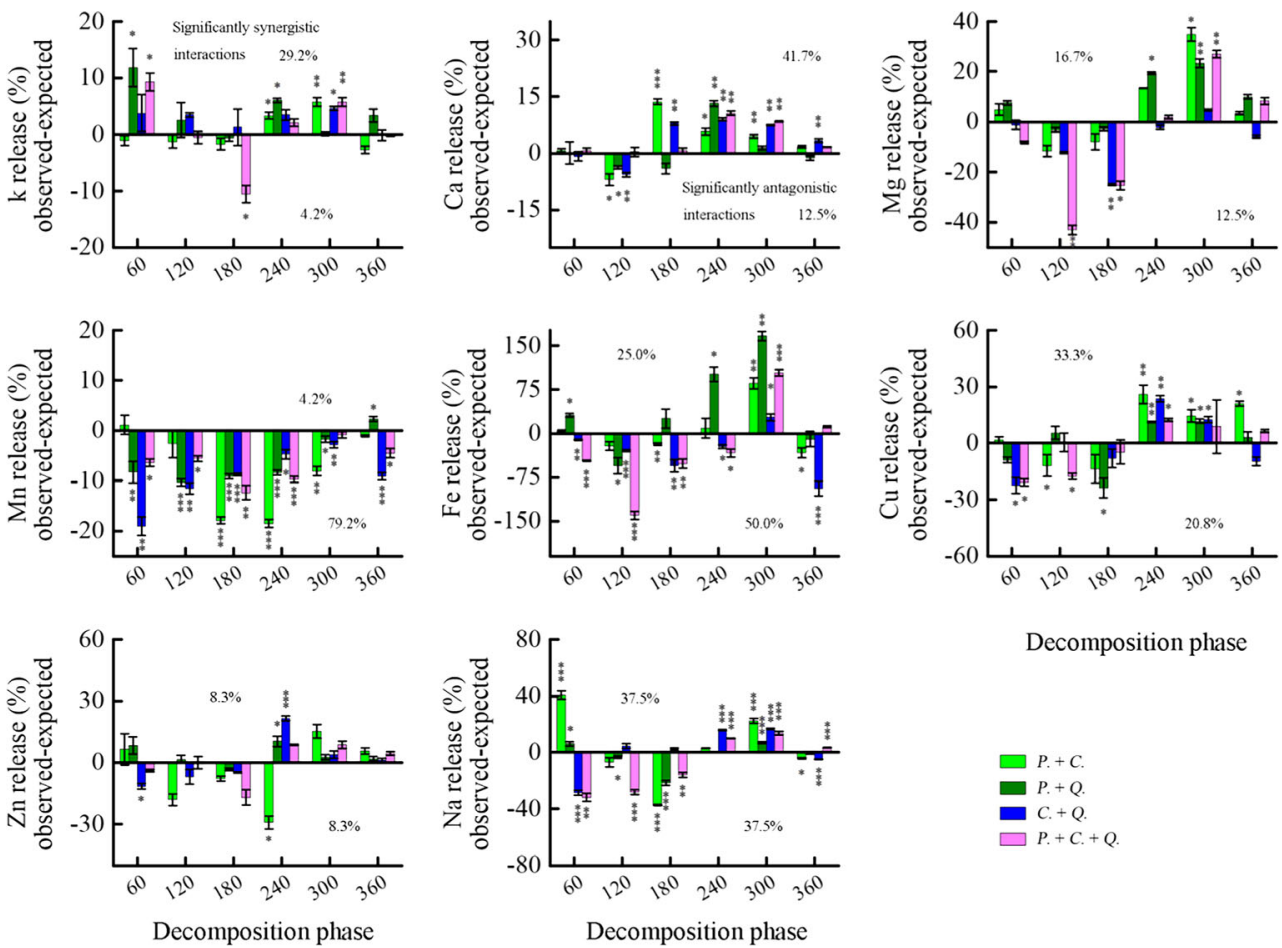

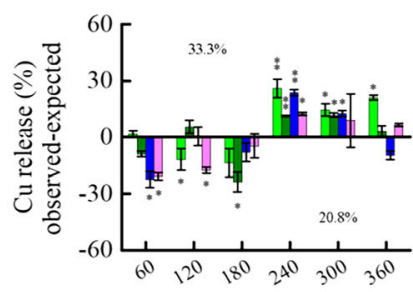

Decomposition phase 
Fig. 5 Effects of the treatments on the metallic element release rates at different decomposition phases. The values are presented as the means \pm SEs $(n=3)$. A positive value indicates that the observed value is greater than the expected value and vice versa.

Statistical significance levels: *, $P<0.05$; **, $P<0.01$; and ***, $P<0.001$. The inset values indicate the proportion of corresponding significant interactions (synergistic and antagonistic interactions above and below the zero line, respectively) in a total of 24 cases.

Treatments: $P .+C ., P$.

massoniana $+C$. funebris; $P .+$ $Q ., P$. massoniana $+Q$.

variabilis; and so on
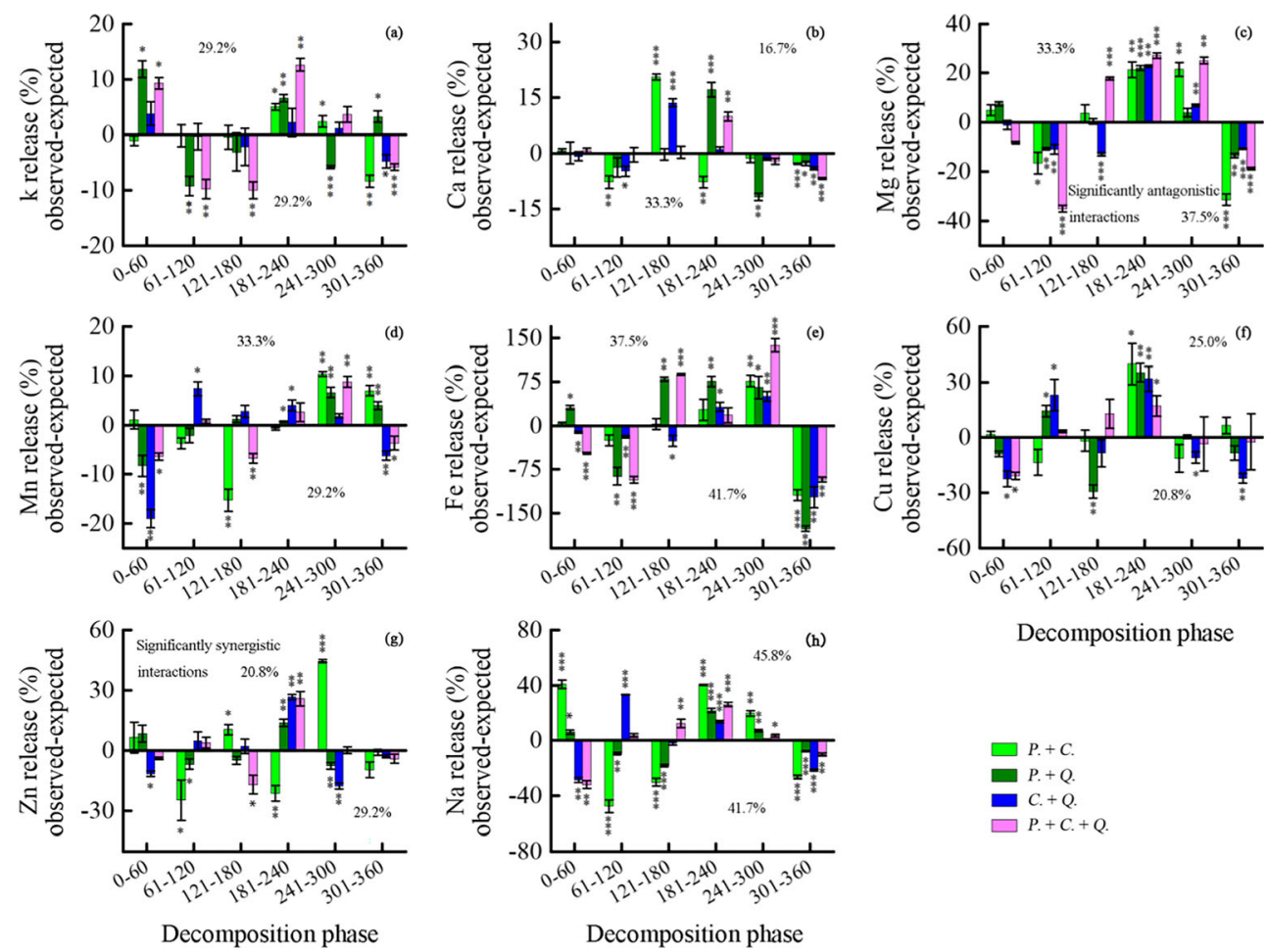

Decomposition phase

Decomposition phase

Table 4 Regression analyses of the mixing effect on metallic element release rates (\%, calculations are based on each phase as a result of observed value minus expected value) and changes in the chemical traits and environmental factors

\begin{tabular}{|c|c|c|c|c|c|c|c|c|c|c|c|c|c|}
\hline Index & $\mathrm{C}$ & $\mathrm{N}$ & $\mathrm{P}$ & K & $\mathrm{Ca}$ & $\mathrm{Mg}$ & $\mathrm{Mn}$ & $\mathrm{Fe}$ & $\mathrm{Cu}$ & $\mathrm{Zn}$ & $\mathrm{Na}$ & AT & $\begin{array}{l}\text { Cumulative } \\
\text { precipitation }\end{array}$ \\
\hline $\mathrm{K}_{\text {release }}$ & 0.031 & 0.076 & 0.001 & 0.026 & 0.001 & 0.004 & 0.002 & 0.001 & $\begin{array}{l}(+) \\
0.06- \\
4^{*}\end{array}$ & $\begin{array}{l}(+) \\
0.10- \\
6^{* * * *}\end{array}$ & 0.053 & 0.007 & 0.007 \\
\hline $\begin{array}{l}\mathrm{Ca} \\
\text { release }\end{array}$ & 0.028 & $\begin{array}{l}(+) \\
0.08- \\
2^{*}\end{array}$ & 0.028 & 0.001 & 0.026 & 0.015 & 0.004 & 0.003 & $\begin{array}{l}(+) \\
0.09- \\
1^{*}\end{array}$ & 0.011 & 0.027 & 0.039 & 0.035 \\
\hline $\begin{array}{l}\mathrm{Mg} \\
\text { release }\end{array}$ & 0.024 & 0.002 & 0.038 & $\begin{array}{l}(-) \\
0.08- \\
6^{*}\end{array}$ & $\begin{array}{l}(-) \\
0.10- \\
5^{* *}\end{array}$ & $\begin{array}{l}(+) \\
0.15- \\
7^{* *}\end{array}$ & 0.013 & ${ }_{\substack{0.186-\\
* * *}}^{(+)}$ & $\begin{array}{l}\text { (+) } \\
0.54- \\
8^{* * * *}\end{array}$ & $\begin{array}{l}\text { (+) } \\
0.18- \\
0^{* * * *}\end{array}$ & $\begin{array}{l}(-) \\
0.09- \\
7^{* * *}\end{array}$ & ${ }_{\substack{0.378-\\
* * *}}$ & (+) $0.093^{* * * *}$ \\
\hline $\begin{array}{l}\mathrm{Mn} \\
\quad \text { release }\end{array}$ & $\begin{array}{l}(-) \\
0.16- \\
3^{* * * * *}\end{array}$ & $\begin{array}{l}(-) \\
0.18- \\
5^{* * * *}\end{array}$ & $\begin{array}{l}(-) \\
0.20- \\
4^{* * * * *}\end{array}$ & $\begin{array}{l}(-) \\
0.17- \\
1^{* * * *}\end{array}$ & $\begin{array}{l}(-) \\
0.15- \\
0^{* *}\end{array}$ & $\begin{array}{l}(+) \\
0.21- \\
9^{* * * *}\end{array}$ & 0.002 & $\stackrel{\substack{0.195-\\
* * * *}}{(+)}$ & 0.029 & 0.014 & 0.000 & (+) & (+) $0.205^{* * * *}$ \\
\hline Fe release & 0.014 & 0.003 & 0.003 & 0.045 & 0.047 & $\begin{array}{l}(+) \\
0.12- \\
6^{* *}\end{array}$ & 0.009 & $\stackrel{(+)}{0.118-}$ & $\begin{array}{l}(+) \\
0.56- \\
6^{* * * *}\end{array}$ & $\begin{array}{l}(+) \\
0.27- \\
8^{* * * *}\end{array}$ & 0.002 & $\begin{array}{l}(+) \\
0.273- \\
* * *\end{array}$ & (+) $0.277^{* * * *}$ \\
\hline $\begin{array}{l}\mathrm{Cu} \\
\quad \text { release }\end{array}$ & 0.006 & 0.027 & 0.000 & 0.032 & 0.030 & 0.001 & 0.008 & 0.000 & $\begin{array}{l}(+) \\
0.09- \\
4^{* * *}\end{array}$ & $\begin{array}{l}(-) \\
0.08- \\
2^{*}\end{array}$ & 0.017 & ${ }^{(+)} 0.117-$ & (+) $0.063^{*}$ \\
\hline $\begin{array}{l}\mathrm{Zn} \\
\quad \text { release }\end{array}$ & 0.025 & 0.016 & 0.002 & 0.006 & 0.008 & 0.024 & 0.860 & 0.206 & $\begin{array}{l}\text { (+) } \\
0.10- \\
7^{* *}\end{array}$ & $\begin{array}{l}(+) \\
0.10- \\
7^{* * *}\end{array}$ & 0.010 & (+) $0.061^{*}$ & 0.032 \\
\hline $\begin{array}{l}\mathrm{Na} \\
\text { release }\end{array}$ & 0.003 & 0.016 & 0.042 & 0.012 & 0.033 & 0.029 & 0.000 & 0.031 & $\begin{array}{l}\text { (+) } \\
0.20- \\
8^{* * * *}\end{array}$ & 0.019 & 0.007 & ${ }^{(+)} 0.124-$ & (+) $0.028^{*}$ \\
\hline
\end{tabular}

The values shown are the determination coefficients $\left(R^{2}\right)$ obtained from the regression analyses, which were conducted using the mixing effects on the metallic element release rate (the observed value minus the expected value) as the response variables and the changes in the chemical traits or environmental factors as the predictor variables over the 360-day decomposition experiment

$A T$, average temperature; (+), positive relationship; (-), negative relationship; significance (italics): $*<<0.05 ; * * P<0.01 ; * * * P<0.001 ; n=52$ (A); $n=72(\mathrm{~B})$ 


\subsection{Effects of changes in litter quality with environmental hydrothermal dynamics on nonadditive metallic element release}

$\mathrm{K}, \mathrm{Ca}$, and $\mathrm{Mg}$ are essential macronutrients for plant growth, and their release pattern in decomposing litter can display a release tendency that is even faster than that of $\mathrm{N}$ and $\mathrm{P}$ (Prescott 2005). The mechanism underlying this high release rate depends on the mobile characteristics of these elements and is easily influenced by leaching (Edmonds and Tuttle 2010). In our study, however, the nonadditive effects of $\mathrm{Ca}$ and $\mathrm{Mg}$ were found after 120 days of incubation (no obvious release was detected during the first 60 days) (Fig. 4). In addition, the nonadditive effects of $\mathrm{Ca}, \mathrm{Mg}$, and $\mathrm{Cu}$ decreased during the various decomposition phases compared with decomposition over time (Figs. 4 and 5), which suggested that the relative "difficulty" in the release of these elements induced less frequent interactions during a short decomposition time. This phenomenon might be explained by the improved physical microenvironmental conditions for decomposition obtained with an admixture of diverse types of litter with different surface shapes (Makkonen et al. 2013). The "hold back" for component litter in mixtures might mask the synergistic interactions, and a net additive or nonadditive release might thus be observed for these elements. In contrast, our findings suggest that planting a mixture of the three predominant afforestation trees can exert immediate mixing effects on the release of the remaining metallic elements that were investigated in this experiment.

In addition, although $\mathrm{Na}$ is not an important element for plants, it is essential for litter decomposers (particularly soil microbes) (Yue et al. 2016), which can, in turn, regulate the decomposition process and the simultaneous elemental decay dynamics (Table 3). A previous study reported that litter decomposers must assimilate $\mathrm{Na}$ at rates up to approximately 100- to 1000-fold higher than those of the decomposing litter to retain a $\mathrm{Na}$ balance (depending on the metabolic needs of the specific microbes) (Cromack et al. 1977). This result suggests that the decay pattern of $\mathrm{Na}$ can show marked variations according to the Na balance of the litter decomposers because neither insufficient nor excessive $\mathrm{Na}$ would be favorable for consumers (Jia et al. 2015). In our study, the $\mathrm{Na}$ in all the treatments showed accumulation during the first 60 days of incubation and then exhibited release as the decomposition process continued to proceed, which is similar to the results reported by Yue et al. (2016). Importantly, our findings further suggest that mixed tree planting can facilitate the release of $\mathrm{Na}$ after incubation for 240 days (due to nonadditive effects during the decomposition process, Fig. 3).

Furthermore, previous experiments on the decomposition of various species and sites have documented both the release (Aponte et al. 2012; Lomander and Johansson 2001) and the accumulation (Jonczak et al. 2014; Windham et al. 2004) dynamics of $\mathrm{Mn}, \mathrm{Fe}, \mathrm{Cu}$, and $\mathrm{Zn}$. In our study, the litter quality changed as decomposition progressed; thus, the litter quality can show markedly variations among different decomposition phases and litter mixtures (Fig. 1) and thereby influences the element release pattern and the associated nonadditive effects (Figs. 3 and 5). Our results, consistent with those obtained in previous studies, indicate that the sorption of metallic metals in decomposing litter might contribute to potential mechanisms, such as the formation of chelates and complexes (Odum and Drifmeyer 1978) and the accumulation of elements from the external environment by fungi (particularly Fe in our study) (Gadd and Griffiths 1978), whereas release is observed if the amount of an element exceeds a certain threshold (Edmonds and Tuttle 2010). In addition, in this study, we presented the release or sorption of elements weighted by their initial content. Notably, "concentration effects" with environmental hydrothermal dynamics may have a large influence on the release or sorption processes that strengthen the influence of biological fixation. The findings obtained in this study further suggest that specific decomposition phases (caused by different elemental traits and environmental hydrothermal dynamics) can regulate mixing effects on elemental decay in litter mixtures. Moreover, we found that the mixing effects on the investigated metallic elements, with the exception of $\mathrm{Mn}$, were significantly related to most of the changes in the quality of the metallic elements and the environmental factors. Because $\mathrm{Mn}$ is essential for the activity of $\mathrm{Mn}$ peroxidase and lignin-degrading enzymes (Perez and Jeffries 1992), the fact that $\mathrm{Mn}$ was an exception to the pattern might be explained by the lower net effects of multiple processes as mass loss progresses (Aponte et al. 2012).

\section{Conclusion}

In summary, our results indicate that the implementation of mixed planting with Masson pine (Pinus massoniana Lamb.), weeping cypress (Cupressus funebris Endl.), and cork oak (Quercus variabilis $\mathrm{Bl}$.) trees could alter the decay dynamics of multiple metallic elements in litter mixtures and induce nonadditive effects as decomposition proceeds. In support of the current consensus, $\mathrm{K}$ showed a consistently rapid release rate and could exhibit synergistic interactions in the litter mixtures. However, $\mathrm{Ca}$ and $\mathrm{Mg}$ had rapid release rates but hysteretic and lower incidences of nonadditive effects. These results indicate that the chemical characteristics of the elements regulate their decay processes. In addition, although the release rates of $\mathrm{Mn}, \mathrm{Fe}, \mathrm{Cu}, \mathrm{Zn}$, and $\mathrm{Na}$ showed marked variations, our results confirmed that their release was facilitated in the litter mixtures. The findings obtained in this study suggest that the species compositions and specific decomposition phases can regulate the mixing effects on elemental decay in litter mixtures. Furthermore, the greater release or accumulation 
of metallic elements obtained with the pine+oak and cypress+ oak combination compared with the pine+cypress+oak combination further indicates that the magnitude of the mixing effects relies more on the species composition than on the species richness. The present study also showed that the litter quality of oak exhibited superior (relatively less recalcitrant) characteristics that likely contribute to the cycling of most element cycles, and thus, to the acceleration of element circulation in situ. Our results suggest that broad-leafed species, such as Quercus variabilis, are preferential tree species for mixed planting with coniferous species (such as Pinus massoniana and Cupressus funebris in the study area). This research provides a better understanding of the fate of multiple metallic elements in situ and provides useful information for the process management of selected tree species. Researchers should further investigate the decomposition dynamics on mixed forest floors directly and consider the realistic mass ratio of natural litter components.

Acknowledgments We are grateful to Dr. Danju Zhang for the constructive comments, which helped improved the manuscript.

Funding information This work was supported by the Fundamental Research Funds for the Central Nonprofit Research Institution of CAF (No. CAFYBB2018QB004), the National Natural Science Foundation of China (No. 31800518 and 31870611), the Fundamental Research Funds for the Central Universities (No. 2662018PY084), and the Hubei Provincial Natural Science Foundation of China (2018CFB374).

Data availability The datasets generated and/or analyzed during the current study are available in the Figshare repository, https://doi.org/10. 6084/m9.figshare.12058656.v2

Compliance with ethical standards The Institute of College of Horticulture and Forestry Sciences, Huazhong Agricultural University, has had a permit from the Zigui county Forestry Bureau to conduct scientific experiments in the Three Gorges Reservoir area of China since May 2006. The senescent fresh leaf litter collected for this study was only sampled at a very limited scale, and thus had negligible effects on broader ecosystem functioning. Moreover, this research was carried out in compliance with the laws of the People's Republic of China. The research did not involve measurements on humans or animals and no endangered or protected plant species was involved.

Conflict of interest The authors declare that they have no conflict of interest.

\section{References}

Aponte C, García LV, Marañón T (2012) Tree species effect on litter decomposition and nutrient release in Mediterranean oak forests changes over time. Ecosystems 15:1204-1218. https://doi.org/10. 1007/s10021-012-9577-4

Ayres E, Steltzer H, Simmons BL, Simpson RT, Steinweg JM, Wallenstein MD, Mellor N, Parton WJ, Moore JC, Wall DH (2009) Home-field advantage accelerates leaf litter decomposition in forests. Soil Biol Biochem 41:606-610. https://doi.org/10.1016/j. soilbio.2008.12.022
Briones MJI, Ineson P (1996) Decomposition of eucalyptus leaves in litter mixtures. Soil Biol Biochem 28:1381-1388. https://doi.org/ 10.1016/S0038-0717(96)00158-7

Brunel C, Gros R, Ziarelli F, Da Silva AMF (2017) Additive or nonadditive effect of mixing oak in pine stands on soil properties depends on the tree species in Mediterranean forests. Sci Total Environ 590-591:676-685. https://doi.org/10.1016/j.scitotenv.2017.03.023

Chapin FS III, Matson PA, Vitousek P (2002) Principles of terrestrial ecosystem ecology. Springer, New York

Chomel M, Guittonny-Larchevêque M, Desrochers A, Baldy V (2015) Home field advantage of litter decomposition in pure and mixed plantations under boreal climate. Ecosystems 18:1014-1028. https://doi.org/10.1007/s10021-015-9880-y

Cornwell WK, Cornelissen JHC, Amatangelo K, Dorrepaal E, Eviner VT, Godoy O, Hobbie SE, Hoorens B, Kurokawa H, PérezHarguindeguy N, Quested HM, Santiago LS, Wardle DA, Wright IJ, Aerts R, Allison SD, Van Bodegom P, Brovkin V, Chatain A, Callaghan TV, Díaz S, Garnier E, Gurvich DE, Kazakou E, Klein JA, Read J, Reich PB, Soudzilovskaia NA, Vaieretti MV, Westoby M (2008) Plant species traits are the predominant control on litter decomposition rates within biomes worldwide. Ecol Lett 11:10651071. https://doi.org/10.1111/j.1461-0248.2008.01219.x

Cuchietti A, Marcotti E, Gurvich DE, Cingolani AM, Pérez Harguindeguya N (2014) Leaf litter mixtures and neighbour effects: low-nitrogen and high-lignin species increase decomposition rate of high-nitrogen and low-lignin neighbours. Appl Soil Ecol 82:44-51. https://doi.org/10.1016/j.apsoil.2014.05.004

Duan JC, Wang SP, Zhang ZH, Xu GP, Luo CY, Chang XF, Zhu XX, Cui SJ, Zhao XQ, Wang WY, Du MY (2013) Non-additive effect of species diversity and temperature sensitivity of mixed litter decomposition in the alpine meadow on Tibetan Plateau. Soil Biol Biochem57:841-847. doi:https://doi.org/10.1016/j.soilbio.2012.08. 009

Edmonds RL, Tuttle KM (2010) Red alder leaf decomposition and nutrient release in alder and conifer riparian patches in western Washington, USA. Forest Ecol Manag 259:2375-2381. https://doi. org/10.1016/j.foreco.2010.03.011

FAO (2015) Global forest resources assessment 2015. FAO forestry paper, Food and Agriculture Organization of the United Nations, Rome

Finzi AC, Canhamb CD (1998) Non-additive effects of litter mixtures on net $\mathrm{N}$ mineralization in a southern New England forest. Forest Ecol Manag 105:129-136. https://doi.org/10.1016/S0378-1127(97) 00277-6

Gadd GM, Griffiths AJ (1978) Microorganisms and heavy metal toxicity. Microb Ecol 4:303-317

Gartner TB, Cardon ZG (2004) Decomposition dynamics in mixedspecies leaf litter. Oikos 104:230-246. https://doi.org/10.1111/j. 0030-1299.2004.12738.x

Ge XG, Zeng LX, Xiao WF, Huang ZL, Zhou BZ (2015) Dynamic of leaf litter stoichiometric traits dynamic and its relations with decomposition rates under three forest types in Three Gorges Reservoir Area. Acta Ecol Sin 35:779-787 [in Chinese, English abstract]

Gessner MO, Swan CM, Dang CK, McKie BG, Bardgett RD, Wall DH, Hättenschwiler S (2010) Diversity meets decomposition. Trends Ecol Evol 25:372-380. https://doi.org/10.1016/j.tree.2010.01.010

Harrison AF (1971) The inhibitory effect of oak leaf litter tannins on the growth of fungi, in relation to litter decomposition. Soil Biol Biochem 3:167-172. https://doi.org/10.1016/0038-0717(71) 90011-3

Hättenschwiler S, Tiunov AV, Scheu S (2005) Biodiversity and litter decomposition in terrestrial ecosystems. Annu Rev Ecol Evol S 36:191-218. https://doi.org/10.1146/annurev.ecolsys.36.112904. 151932

He J, Yang WQ, Xu LY, Ni XY, Li H, Wu FZ (2015) Copper and zinc dynamics in foliar litter during decomposition from gap center to 
closed canopy in an alpine forest. Scand J Forest Res 31:355-367. https://doi.org/10.1080/02827581.2015.1078405

He W, Ma ZY, Pei J, Teng MJ, Zeng LX, Yan ZG, Huang ZL, Zhou ZX, Wang PC, Luo X, Xiao WF (2019) Effects of predominant tree species mixing on lignin and cellulose degradation during leaf litter decomposition in the Three Gorges Reservoir, China. Forests 10: 360. https://doi.org/10.3390/f10040360

He W, Lei L, Ma ZY, Teng MJ, Wang PC, Yan ZG, Huang ZL, Zeng LX, Xiao WF (2020) Nonadditive effects of decomposing mixed foliar litter on the release of several metallic elements in a Pinus massoniana Lamb. Forest. V1. Figshare. [dataset]. https://doi.org/ 10.6084/m9.figshare.12058656.v2

Jia Y, Kong X, Weiser MD, Lv Y, Akbar S, Jia X, Tian K, He Z, Lin H, Bei $Z$ (2015) Sodium limits litter decomposition rates in a subtropical forest: additional tests of the sodium ecosystem respiration hypothesis. Appl Soil Ecol 93:98-104. https://doi.org/10.1016/j. apsoil.2015.04.012

Jonczak J, Parzych A, Sobisz Z (2014) Dynamics of Cu, Mn, Ni, Sr and $\mathrm{Zn}$ release during decomposition of four types of litter in headwater riparian forests in northern Poland. Leśne Prace Badawcze (For Res Papers) 75:193-200. https://doi.org/10.2478/frp-2014-0018

Keith AM, Van Der Wal R, Brooker RW, Osler GHR, Chapman SJ, Burslem DFRP, Elston DA (2008) Increasing litter species richness reduces variability in a terrestrial decomposer system. Ecology 89: 2657-2664. https://doi.org/10.1890/07-1364.1

Cromack, K Jr, Sollins P, Todd RL, Crossley DA Jr, Fender WM, Fogel R, Todd AW (1977) Soil microorganism-arthropod interactions: fungi as major calcium and sodium sources. In: Mattson W (ed) The role of arthropods in forest ecosystems. Springer, Berlin Heidelberg, pp 78-84

Lecerf A, Risnoveanu G, Popescu C, Gessner MO, Chauvet E (2007) Decomposition of diverse litter mixtures in streams. Ecology 88: 219-227. https://doi.org/10.1890/0012-9658(2007)88[219: DODLMI 2.0.CO;2

Liu CC, Liu YG, Guo K, Zhao HW, Qiao XG, Wang SJ, Zhang L, Cai XL (2016) Mixing litter from deciduous and evergreen trees enhances decomposition in a subtropical karst forest in southwestern China. Soil Biol Biochem 101:44-54. https://doi.org/10.1016/j. soilbio.2016.07.004

Lomander A, Johansson MB (2001) Changes in concentrations of Cd, $\mathrm{Zn}, \mathrm{Mn}, \mathrm{Cu}$ and $\mathrm{Pb}$ in spruce (Picea abies) needle litter during decomposition. Water Air Soil Pollut 132:165-184

Makkonen M, Berg MP, van Logtestijn RSP, van Hal JR, Aerts R (2013) Do physical plant litter traits explain non-additivity in litter mixtures? A test of the improved microenvironmental conditions theory. Oikos 122:987-997. https://doi.org/10.1111/j.1600-0706.2012. 20750.x

Mao B, Zeng DH (2012) Non-additive effects vary with the number of component residues and their mixing proportions during residue mixture decomposition: a microcosm study. Geoderma 170:112117. https://doi.org/10.1016/j.geoderma.2011.11.008

McTiernan KB, Ineson P, Coward PA (1997) Respiration and nutrient release from tree leaf litter mixtures. Oikos 78:527-538

Odum WE, Drifmeyer JE (1978) Sorption of pollutants by plant detritus: a review. Environ Health Perspect 27:133-137. https://doi.org/10. 1289/ehp.7827133

Perez J, Jeffries TW (1992) Roles of manganese and organic acid chelators in regulating lignin degradation and biosynthesis of peroxidases by Phanerochaete chrysosporium. Appl Environ Microbiol 58: 2402-2409

Pérez HN, Blundo CM, Gurvich DE, Díaz S, Cuevas E (2007) More than the sum of its parts? Assessing litter heterogeneity effects on the decomposition of litter mixtures through leaf chemistry. Plant Soil 303:151-159. https://doi.org/10.1007/s11104-007-9495-y
Prescott C (2005) Decomposition and mineralization of nutrients from litter and humus. In: BassirRad $\mathrm{H}$ (ed) Nutrient acquisition by plants: an ecological perspective. Springer, Berlin, pp 125-141

Rodriguez-Loinaz G, Onaindia M, Amezaga I, Mijangos I, Garbisu C (2008) Relationship between vegetation diversity and soil functional diversity in native mixed-oak forests. Soil Biol Biochem 40:49-60. https://doi.org/10.1016/j.soilbio.2007.04.015

Staaf H, Berg B (1982) Accumulation and release of plant nutrients in decomposing Scots pine needle litter. Long-term decomposition in a Scots pine forest II. Can J Bot 60:1561-1568. https://doi.org/10. 1139/b82-199

Steinwandter M, Schlick-Steiner BC, Steiner FM, Seeber J (2019) One plus one is greater than two: mixing litter types accelerates decomposition of low-quality alpine dwarf shrub litter. Plant Soil 438:405419. https://doi.org/10.1007/s11104-019-03991-5

Sun X, Kang HZ, Du HM, Hu HB, Zhou JB, Jl H, Zhou X, Liu CJ (2012) Stoichiometric traits of oriental oak (Quercus variabilis) acorns and their variations in relation to environmental variables across temperate to subtropical China. Ecol Res 27:765-773. https://doi.org/10. 1007/s11284-012-0953-5

Swan CM, Gluth MA, Horne CL (2009) Leaf litter species evenness influences nonadditive breakdown in a headwater stream. Ecology 90:1650-1658. https://doi.org/10.1890/08-0329.1

Swift MJ, Heal OW, Anderson JM (1979) Decomposition in terrestrial ecosystems. University of California Press

Vivanco L, Austin AT (2008) Tree species identity alters forest litter decomposition through long-term plant and soil interactions in Patagonia, Argentina. J Ecol 96:727-736. https://doi.org/10.1111/j. 1365-2745.2008.01393.x

Windham L, Weis JS, Weis P (2004) Metal dynamics of plant litter of Spartina alterniflora and Phragmites australis in metal-contaminated salt marshes. Part 1: patterns of decomposition and metal uptake. Environ Toxicol Chem 23:1520-1528. doi:https://doi.org/10.1897/ 03-284

Wu DD, Li TT, Wan SQ (2013) Time and litter species composition affect litter-mixing effects on decomposition rates. Plant Soil 371: 355-366. https://doi.org/10.1007/s11104-013-1697-x

Wu FZ, Peng CH, Yang WQ, Zhang J, Han Y, Mao T (2014) Admixture of alder (Alnus formosana) litter can improve the decomposition of eucalyptus (Eucalyptus grandis) litter. Soil Biol Biochem 73:115121. https://doi.org/10.1016/j.soilbio.2014.02.018

Yue K, Yang WQ, Peng Y, Zhang C, Huang CP, Xu ZF, Tan B, Wu FZ (2016) Dynamics of multiple metallic elements during foliar litter decomposition in an alpine forest river. Ann Forest Sci 73:1-11. https://doi.org/10.1007/s13595-016-0549-2

Yue K, Yang WQ, Tan B, Peng Y, Huang CP, Xu ZF, Ni XY, Yang Y, Zhou W, Zhang L, Wu FZ (2019) Immobilization of heavy metals during aquatic and terrestrial litter decomposition in an alpine forest. Chemosphere 216:419-427. https://doi.org/10.1016/j.chemosphere. 2018.10.169

Zeng LX, He W, Teng MJ, Luo X, Yan ZG, Huang ZL, Zhou ZX, Wang PC, Xiao WF (2018) Effects of mixed leaf litter from predominant afforestation tree species on decomposition rates in the Three Gorges Reservoir, China. Sci Total Environ 639:679-686. https:// doi.org/10.1016/j.scitotenv.2018.05.208

Zhu JX, Hu HF, Tao SL, Chi XL, Li P, Jiang LL, Ji CJ, Zhu JL, Tang ZY, Pan YD, Birdsey RA, He XH, Fang JY (2017) Carbon stocks and changes of dead organic matter in China's forests. Nat Commun 8: 151. https://doi.org/10.1038/s41467-017-00207-1

Publisher's note Springer Nature remains neutral with regard to jurisdictional claims in published maps and institutional affiliations. 